GÓIS, Rômulo Lima Silva de; VERGES, João Vitor Gobis e LUNA, Braúlio José Carvalhal. Ordenamento do território face às dinâmicas climáticas: comparações entre o projeto orla brasileiro, o zoneamento ecológico-econômico costeiro e o programa buyout estadunidense. Revista Eletrônica Direito e Política, Programa de Pós-Graduação Stricto Sensu em Ciência Jurídica da UNIVALI, Itajaí, v.10, n.4, 30 quadrimestre de 2015 . Disponível em: www.univali.br/direitoepolitica - ISSN 1980-7791.

\title{
ORDENAMENTO DO TERRITÓRIO FACE ÀS DINÂMICAS CLIMÁTICAS: COMPARAÇÕES ENTRE O PROJETO ORLA BRASILEIRO, $O$ ZONEAMENTO ECOLÓGICO-ECONÔMICO COSTEIRO E O PROGRAMA BUYOUT ESTADUNIDENSE
}

\author{
SPATIAL PLANNING AGAINST CLIMATE DYNAMICS: COMPARISONS \\ BETWEEN THE BRAZILIAN ORLA PROJECT, THE ECOLOGICAL-ECONOMIC \\ ZONING AND U.S. BUYOUT PROGRAM
}

\author{
Rômulo Lima Silva de Góis ${ }^{1}$ \\ João Vitor Gobis Verges ${ }^{2}$ \\ Braúlio José Carvalhal Luna ${ }^{3}$
}

SUMÁRIO: Introdução; 1 . Enquadramento analítico. Ordenamento do território e dinâmicas climáticas; 2. O Projeto Orla Brasileiro E O Desenvolvimento Do Zoneamento Ecológico-Econômico Costeiro; 3. O Programa Buyout Estadunidense Como Política Pública Territorial De Adaptação Transformacional; Considerações Finais; Referências das Fontes Citadas

\section{RESUMO}

Propõe-se uma discussão sobre a importância do Ordenamento do Território para o ambiente costeiro e sua relação direta com os riscos ocasionados pelas dinâmicas climáticas a partir de uma análise comparativa entre o Plano Buyout dos Estados Unidos e o Projeto Orla brasileiro. Utiliza-se a análise e revisão de levantamento de dados bibliográficos. Atinge-se como principal conclusão que quando uma política pública preventiva não se apresenta mais como promotora

\footnotetext{
${ }^{1}$ Doutorando em Ciências Ambientais na Faculdade de Ciências e Tecnologia, Universidade Nova de Lisboa, Bolsista para Doutorado Pleno pela Capes, Processo no 1471-13-9, Lisboa, Portugal, romulo.gois@yahoo.com.br

2 Doutorando em Ciências Ambientais, Faculdade de Ciências, Universidade de Lisboa, Bolsista para Doutorado Pleno pela Capes, Processo no 9719-13-0, Lisboa, Portugal, vitorverges@gmail.com

3 Doutorando em Ciências Ambientais, Faculdade de Ciências, Universidade de Lisboa, Campina Grande/PB, Brasil; bjcluna@hotmail.com
} 
GÓIS, Rômulo Lima Silva de; VERGES, João Vitor Gobis e LUNA, Braúlio José Carvalhal. Ordenamento do território face às dinâmicas climáticas: comparações entre o projeto orla brasileiro, o zoneamento ecológico-econômico costeiro e o programa buyout estadunidense. Revista Eletrônica Direito e Política, Programa de Pós-Graduação Stricto Sensu em Ciência Jurídica da UNIVALI, Itajaí, v.10, n.4, 30 quadrimestre de 2015 . Disponível em: www.univali.br/direitoepolitica - ISSN 1980-7791.

de adaptação ao aumento do nível do mar a mesma deve considerar soluções mais coercivas por parte do Estado.

PALAVRAS-CHAVE: Riscos; Planejamento Costeiro; Erosão Marítima; Políticas Públicas.

\section{ABSTRACT}

This paper proposes a critical discussion about the importance of Spatial Planning for the coastal environment and its direct relation to the risks caused by climate dynamics from a comparative analysis between the U.S. Buyout Plan and the Brazilian Orla Project. The methodology includes the analysis and review of bibliographic and review of management plans coast. Reaches the main conclusion that the preventive public policy is not presented more as a promoter of possible adaptation to rising sea level and sea erosion, it should consider more coercive solutions by the state and face these problems.

KEYWORDS: Risk; Coastal Planning; Coastal erosion; Public Policy.

\section{INTRODUÇÃO}

As zonas urbanas possuem historicamente função contributiva para garantir descobertas, avanços científicos e alterações progressistas nas relações humanas como espaços excepcionais do encontro, da comunicação, do intercâmbio e concentração de informações.

Segundo a Organização para Cooperação e Desenvolvimento Econômico $(\mathrm{OCDE})^{4}$, as cidades constituem centros da economia global, sendo responsáveis por grande parte da produção nacional de cada país, da inovação e emprego, constituindo, ainda, os principais pontos de entradas dos fluxos de capitais globais e de cadeias de suprimentos transnacionais.

Recentemente, num contexto de priorização do crescimento econômico e de crise ambiental sem precedentes, a vulnerabilidade das cidades às dinâmicas

\footnotetext{
${ }^{4}$ ORGANIZAÇÃO PARA COOPERAÇÃO E DESENVOLVIMENTO ECONÔMICO - OCDE. Competitive
} Cities in the Global Economy. Paris: OECD Publications, 2006, p.1. 
GÓIS, Rômulo Lima Silva de; VERGES, João Vitor Gobis e LUNA, Braúlio José Carvalhal. Ordenamento do território face às dinâmicas climáticas: comparações entre o projeto orla brasileiro, o zoneamento ecológico-econômico costeiro e o programa buyout estadunidense. Revista Eletrônica Direito e Política, Programa de Pós-Graduação Stricto Sensu em Ciência Jurídica da UNIVALI, Itajaí, v.10, n.4, 30 quadrimestre de 2015 . Disponível em: www.univali.br/direitoepolitica - ISSN 1980-7791.

climáticas permanece como um desafio que vem sendo enfrentado vagarosamente.

Diversos estudos, além da apresentação do quinto relatório pelo Painel Intergovernamental para as Mudanças Climáticas - IPCC (AR5) ${ }^{5}$ demonstram 0 agravamento das dinâmicas climáticas na Terra e por consequência direta as alterações no ambiente em que coabitam os seres vivos, problemática que tem gerado, entre as várias discussões científicas, debates sobre a relevância da relação direta entre o Ordenamento do Território e Dinâmicas climáticas.

Em recente avaliação da $\mathrm{OCDE}^{6}$, duas características claras e marcantes devem ser apresentadas para justificar uma ação adaptativa a médio e longo prazo, quais sejam: o avanço dos cenários futuros projetados e os riscos e danos associados serem extremos, ou até mesmo catastróficos, fatos corroborados por Burniaux et al $^{7}$ e Duval e Maisonneuve ${ }^{8}$.

Em artigo divulgado pela $\mathrm{OCDE}^{9}$, considerando 136 cidades portuárias, o número da população suscetível à elevação do nível do mar, nestas, pode chegar a 40 milhões de pessoas. O valor total de prejuízos projetados foi estimado em U\$ 3 trilhões de dólares, o que correspondeu a 5\% do PIB global em 2005.

\footnotetext{
${ }^{5}$ intergovernamental panel on Climate Change - IPCC. Climate Change 2013: the physical science basis. Disponível em: <http://www.climatechange2013.org/images/report/WG1AR5_ALL_FINAL.pdf>. Acesso em: 04 jun. 2014.
}

${ }^{6}$ ORGANIZAÇÃO PARA COOPERAÇÃO E DESENVOLVIMENTO ECONÔMICO - OCDE. Ranking Port Cities with High Exposure and Vulnerability to Climate Extremes: Exposure Estimates. Environmental working papers, Paris, n. 1, 2008, p. 63-82.

7 BURNIAX, J.; CHATEAU, J.; DELLINK, R.; DUVAL, R.; JAMET. S. The economics of climate change mitigation: how to build the necessary global action in a cost-effective manner?. Paris: OECD Economics Departament Working Papers, 2008, p.109-110.

8 DUVAL, R.; MAISONNEUVE, C. Long-run GDP Growth Scenarios for the World Economy. Paris: OECD Economics Departament Working Papers, 2009, p. 16-17.

9 ORGANIZAÇÃO PARA COOPERAÇÃO E DESENVOLVIMENTO ECONÔMICO - OCDE. Ranking Port Cities with High Exposure and Vulnerability to Climate Extremes: Exposure Estimates. p. 63-82. 
GÓIS, Rômulo Lima Silva de; VERGES, João Vitor Gobis e LUNA, Braúlio José Carvalhal. Ordenamento do território face às dinâmicas climáticas: comparações entre o projeto orla brasileiro, o zoneamento ecológico-econômico costeiro e o programa buyout estadunidense. Revista Eletrônica Direito e Política, Programa de Pós-Graduação Stricto Sensu em Ciência Jurídica da UNIVALI, Itajaí, v.10, n.4, 30 quadrimestre de 2015 . Disponível em: www.univali.br/direitoepolitica - ISSN 1980-7791.

Projeções ainda da $\mathrm{OCDE}^{10}$, demonstram que no final do século, o total da população exposta poderia triplicar para cerca de 150 milhões de pessoas, sendo os prejuízos projetados estimados em mais de 36 trilhões, cerca de $9 \%$ do PIB mundial do ano de 2005.

S. Jamet e J. Morlot-Corfee ${ }^{11}$ estimam que as ações políticas no presente, apesar dos custos elevados, devem ganhar prioridade porque diante de um quadro de grandes incertezas, o que limita o risco maior no futuro é tornar prioritário o combate e ações no presente.

Partindo da relevância exposta da temática proposta, o presente artigo objetiva, sendo estas suas questões de investigação: fazer uma análise sobre a importância do Ordenamento do Território e sua relação direta com as dinâmicas climáticas, discorrendo sobre a capacidade adaptativa das cidades litorâneas que constituem um dos centros receptores dos maiores prejuízos advindos dos azares climáticas, do aumento do nível do mar e da erosão marítima. E sob uma perspectiva mais estrita tentará revelar como um processo social tem repercussões fortes no âmbito territorial e ações diretas nas orlas marítimas precisam priorizar readequações da ocupação e do uso do espaço urbano litorâneo, visando acompanhar um processo global de adaptação às mudanças do clima.

Por objetivos específicos, almejará demonstrar como a delimitação de políticas públicas acertadas e uma gestão integrada para ordenar o uso e a ocupação do solo nas cidades litorâneas e nas suas faixas territoriais juntos aos mares surgem como contributo imensurável para adaptação aos nuances climáticos, trazendo como eixo paradigmático um diálogo entre o Projeto Orla brasileiro e a implantação do Zoneamento Ecológico-Econômico nos planos de gestão da Costa e o Plano Buyout dos Estados Unidos como modelo de adaptação

${ }^{10}$ ORGANIZAÇÃO PARA COOPERAÇÃO E DESENVOLVIMENTO ECONÔMICO - OCDE. Ranking Port Cities with High Exposure and Vulnerability to Climate Extremes: Exposure Estimates. p. 63-82.

11 JAMET, S.; MORLOT-CORFEE, J. Assessing the Impacts of Climate Change: a literature review, Paris: OECD Economics Departament Working Papers, no 693, 2009, p. 20-21. 
GÓIS, Rômulo Lima Silva de; VERGES, João Vitor Gobis e LUNA, Braúlio José Carvalhal. Ordenamento do território face às dinâmicas climáticas: comparações entre o projeto orla brasileiro, o zoneamento ecológico-econômico costeiro e o programa buyout estadunidense. Revista Eletrônica Direito e Política, Programa de Pós-Graduação Stricto Sensu em Ciência Jurídica da UNIVALI, Itajaí, v.10, n.4, 30 quadrimestre de 2015. Disponível em: www.univali.br/direitoepolitica - ISSN 1980-7791.

transformacional quando as adaptações às dinâmicas climáticas já não são suficientes.

A metodologia realizada compreendeu análise qualitativa, onde se utilizou como método a revisão e levantamento de dados bibliográficos, baseado essencialmente numa investigação de referenciais escritos e publicados, sobre as matérias em causa e sobre as áreas de investigações envolvidas.

Utilizou de pesquisa legislativa brasileira e análise do Projeto Orla como política pública de Ordenamento do Território e do uso e regulamentação de territórios costeiros no Brasil e do Plano Buyout estadunidense como política pública territorial de desapropriação para adaptação transformacional, análise esta que possibilitou um estudo comparado entre os dois planos mencionados.

Fez-se, assim, um estudo comparado para buscar conclusões plausíveis sobre a importância da manutenção, ampliação, ou desenvolvimento destas duas medidas como alternativa de adaptação às dinâmicas climáticas.

\section{ENQUADRAMENTO ANALÍtICO. ORDENAMENTO DO TERRITÓRIO E DINÂMICAS CLIMÁTICAS}

Entre inúmeros outros prognósticos, Felipe Duarte Santos ${ }^{12}$ lembra que as dinâmicas climáticas aumentarão a exposição dos territórios em suas várias escalas e sua sensibilidade, fazendo crescer a suscetibilidade a impactos e riscos potenciais que traduzirá uma vulnerabilidade territorial maior, principalmente no contexto dos centros urbanos litorâneos.

O aumento da vulnerabilidade territorial nos centros urbanos litorâneos poderá ser combatido por uma maior capacidade de adaptação, através de políticas públicas acertadas, onde o Ordenamento do Território detém fundamental

12 SANTOS, Filipe Duarte. Alterações Globais. Lisboa: Fundação Francisco Manuel dos Santos, 2012. 
GÓIS, Rômulo Lima Silva de; VERGES, João Vitor Gobis e LUNA, Braúlio José Carvalhal. Ordenamento do território face às dinâmicas climáticas: comparações entre o projeto orla brasileiro, o zoneamento ecológico-econômico costeiro e o programa buyout estadunidense. Revista Eletrônica Direito e Política, Programa de Pós-Graduação Stricto Sensu em Ciência Jurídica da UNIVALI, Itajaí, v.10, n.4, 30 quadrimestre de 2015 . Disponível em: www.univali.br/direitoepolitica - ISSN 1980-7791.

importância para aumentar a capacidade adaptativa dos territórios aos efeitos das dinâmicas climáticas.

No mesmo diapasão, M, Pelling e Manuel Navarrete ${ }^{13}$ apontam que as estratégias de adaptação podem ocorrer por transformação, por transição ou por resiliência, onde o planejamento físico e estratégico do território apresentar-se-ia como medida essencial de adaptação às dinâmicas climáticas.

Numa análise atual, mais complexa e completa sobre a importância do Ordenamento do Território na contribuição do aumento da capacidade adaptativa dos territórios frente às dinâmicas climáticas, João Ferrão ${ }^{14}$ demonstra que o mesmo apresentaria como meio de articulação e coordenação da tomada de decisões políticas.

Sob uma perspectiva mais instrumental, o Ordenamento do Território como política pública visa, entre outros objetivos, a regulação do uso, ocupação e transformação do mesmo e a governança da base territorial.

O valor acrescentado do Ordenamento do Território, nesta linha argumentativa, pode ser analisado por várias perspectivas: através da regulação e disposições de natureza legal e regulamentar; através de orientação estratégica quanto à localização, uso, morfologia e formas de organização territorial preferencial; e através da governança de base territorial pela coordenação de diferentes intervenções, medidas, ações com incidência num mesmo território.

Assim, João Ferrão ${ }^{15}$ defende que o ordenamento do Território pode contribuir para a melhora na qualidade das decisões no domínio das políticas públicas em contextos complexos e contingentes de maior pluralidade de valores, interesses

\footnotetext{
${ }^{13}$ PELLING, M.; NAVARRETE, Manuel. From Resilience to Transformation: the adaptive cyrcle in two Mexican urban centers. Ecology and Society, v. 16, n.2, art. 11, 2011. Disponível em: $<$ http://www.ecologyandsociety.org/vol16/iss2/art11/>. Acesso em: 04 jun. 2014.

${ }^{14}$ FERRÃO, João. Ordenamento do Território como Política Pública. 2 ed. Lisboa: Fundação Calouste Gulbenkian, 2015, p. 46-89 e p. 25-41.

${ }^{15}$ FERRÃO, João. Ordenamento do Território como Política Pública. p. 46-89.
} 
GÓIS, Rômulo Lima Silva de; VERGES, João Vitor Gobis e LUNA, Braúlio José Carvalhal. Ordenamento do território face às dinâmicas climáticas: comparações entre o projeto orla brasileiro, o zoneamento ecológico-econômico costeiro e o programa buyout estadunidense. Revista Eletrônica Direito e Política, Programa de Pós-Graduação Stricto Sensu em Ciência Jurídica da UNIVALI, Itajaí, v.10, n.4, 30 quadrimestre de 2015 . Disponível em: www.univali.br/direitoepolitica - ISSN 1980-7791.

e preferências e crescente descrença dos cidadãos nas instituições, através de um triângulo virtuoso.

A análise desse triângulo virtuoso (valores, interesses, preferências) é de fundamental importância para contextualização do enquadramento analítico proposto, pois caso considerado e observado, numa das pontas do mesmo, o Ordenamento do Território surgiria como meio para articulação de conhecimentos e coordenação de atores apresentando-se como uma inteligência deliberativa de base territorial para tomada de decisões. Na outra ponta, representaria uma forma de inteligência geográfica, já que constituiria um meio de análise das dinâmicas territoriais do presente para embasar prospectivas para o futuro. Sendo fechado o triângulo na representação do Ordenamento do Território como instrumento de uma ética territorial, onde o mesmo apareceria como forma proporcionadora de uma justiça espacial como objetivo e critério de formulação e avaliação de políticas públicas de uso e ocupação do solo.

Partir destas questões de referência e deste enquadramento analítico assume importância basilar, pois o presente estudo apresentará a comparação entre duas políticas públicas de Ordenamento de Território de países distintos sobre a regulação do uso, ocupação e transformação do território em zonas costeiras e como estas podem ser apresentadas, apesar de distintas, como meios de adaptação às dinâmicas climáticas e aos impactos futuros das mesmas nas cidades litorâneas.

\section{O PROJETO ORLA BRASILEIRO E O DESENVOLVIMENTO DO ZONEAMENTO ECOLÓGICO-ECONÔMICO COSTEIRO}

No âmbito de desenvolvimento do ordenamento do território costeiro brasileiro numa visão integrada com as políticas ambientais e patrimoniais sob uma perspectiva de relação mútua que envolve a articulação entre os três entes federativos, Municípios, Estados e Governo Federal, e a sociedade, foi lançado o 
GÓIS, Rômulo Lima Silva de; VERGES, João Vitor Gobis e LUNA, Braúlio José Carvalhal. Ordenamento do território face às dinâmicas climáticas: comparações entre o projeto orla brasileiro, o zoneamento ecológico-econômico costeiro e o programa buyout estadunidense. Revista Eletrônica Direito e Política, Programa de Pós-Graduação Stricto Sensu em Ciência Jurídica da UNIVALI, Itajaí, v.10, n.4, 30 quadrimestre de 2015 . Disponível em: www.univali.br/direitoepolitica - ISSN 1980-7791.

Projeto de Gestão Integrada da Orla Marítima - Projeto Orla, que objetiva entre outras metas a valorização de ações inovadoras de gestão voltadas ao uso sustentável dos recursos naturais e da ocupação dos espaços litorâneos e o desenvolvimento de mecanismos de participação e adequação social para sua gestão integrada.

Jorge Arzabe ${ }^{16}$ afirma que p Projeto Orla surge como instrumento que demonstra uma evidente preocupação do Brasil com as dinâmicas climáticas e alcança diversas dimensões necessárias para o ordenamento territorial, sendo os nuances do nível do mar uma variável que passa a ser considerada sem olhares céticos na proposição do projeto.

Entre os vários instrumentos antevistos e desenvolvidos pelo Projeto Orla há previsão direta à Governança e a interlocução com a sociedade, onde uma das principais fases de sua implantação ocorre na promoção de oficinas municipais de abordagem e construção mútua da ordenação territorial.

A mobilização de atores políticos e lideranças sociais em âmbito estadual antecede a construção e articulação do Projeto com os municípios, sendo a capacitação no âmbito municipal, mais centralizado e local, a principal fase de desenvolvimento do Projeto.

A articulação e ação em âmbito local acontece por meio de oficinas de capacitação municipais e são realizadas com o objetivo de construir o Plano de Gestão integrada, produto final de cada oficina, que elabora diagnósticos, formula cenários e planeja ações, que incluem a regulação da ocupação e uso da faixa litorânea.

\footnotetext{
16 ARZABE, Jorge. Gestão da Zona Costeira e os Terrenos da Marinha. 60fl. Trabalho de Conclusão de Curso (Curso Intensivo de Pós Graduação em Administração Pública). Fundação Getúlio Vargas. Brasília, 2011, p.23-31 e p.50. Disponível em: http://patrimoniodetodos.gov.br/pasta-dearquivos/GESTaO\%20DA\%20ZONA\%20COSTEIRA\%20E\%200S\%20TERRENOS\%20DE\%20MARI NHA.doc>. Acesso em: 04 de junho de 2014.
} 
GÓIS, Rômulo Lima Silva de; VERGES, João Vitor Gobis e LUNA, Braúlio José Carvalhal. Ordenamento do território face às dinâmicas climáticas: comparações entre o projeto orla brasileiro, o zoneamento ecológico-econômico costeiro e o programa buyout estadunidense. Revista Eletrônica Direito e Política, Programa de Pós-Graduação Stricto Sensu em Ciência Jurídica da UNIVALI, Itajaí, v.10, n.4, 30 quadrimestre de 2015. Disponível em: www.univali.br/direitoepolitica - ISSN 1980-7791.

Em cada fase das oficinas municipais consideram-se a adoção de procedimentos padronizados que possibilitam a construção coordenada de um plano de gestão de orla.

As oficinas objetivam a sensibilização social sobre os fundamentos do Projeto Orla, a construção de diagnóstico juntamente com a classificação e delimitação da orla, os cenários futuros para mesma, a sistematização dos quadros de problemas e as linhas de ação voltadas ao enfrentamento e à instalação de instrumentos para uma gestão sustentável através de meios e cronogramas específicos.

Por outro lado, uma das preocupações constantes e pensadas pelo Projeto é a recaracterização dos limites de orla costeira para possibilitar a regulação do uso e quais as áreas delimitadas onde não é possível a edificação.

Dieter Muehe $^{17}$ descreve que a ocupação indevida que acontece ao longo de toda costa brasileira gera o necessário debate sobre a demarcação de zonas especiais onde se considere uma faixa de proteção mínima tendo em vista a aceleração do processo de erosão marítima e os efeitos e impactos da elevação do nível do mar registrado historicamente.

Desta forma, conforme Jorge Arzabe $^{18}$, os limites de proteção da orla são ordenados em forma de limitações impostas pela administração pública, provenientes de regras urbanísticas e ambientais que definem zonas especiais de proibição de construção, que estabelecem, quando não proibidas, gabaritos de construção e ainda zoneamento de usos. Além dos objetivos mais coercitivos de proibição de ocupação e construção existentes, que quando necessário ao interesse público podem justificar a remoção de construções ou limitação das mesmas, tais medidas administrativas possuem ainda eficácia para alcançar

17 MUEHE, Dieter. Definição de limites e tipologias da orla sob os aspectos morfodinâmico e evolutivo. In: BRASIL. Ministério do Meio Ambiente. Secretaria de Qualidade Ambiental; Ministério do Planejamento, Orçamento e Gestão. Secretaria do Patrimônio da União. Projeto orla - subsídios para um projeto de gestão, Brasília, 2006, p. 11.

${ }^{18}$ ARZABE, Jorge. Gestão da Zona Costeira e os Terrenos da Marinha. p.50. 
GÓIS, Rômulo Lima Silva de; VERGES, João Vitor Gobis e LUNA, Braúlio José Carvalhal. Ordenamento do território face às dinâmicas climáticas: comparações entre o projeto orla brasileiro, o zoneamento ecológico-econômico costeiro e o programa buyout estadunidense. Revista Eletrônica Direito e Política, Programa de Pós-Graduação Stricto Sensu em Ciência Jurídica da UNIVALI, Itajaí, v.10, n.4, 30 quadrimestre de 2015. Disponível em: www.univali.br/direitoepolitica - ISSN 1980-7791.

outros objetivos, como por exemplo, evitar os danos causados ao mercado interno pela especulação financeira imobiliária.

É sob esta perspectiva de repensar os limites da Orla e as áreas de proteção a serem delimitadas, que o Plano de Gestão Integrada gerado a partir de um processo participativo de governança em âmbito municipal, previsto no Projeto Orla, em médias e grandes cidades deve seguir, quando existir, as orientações e diretrizes do Zoneamento Ecológico-Econômico Costeiro (ZEEC) que, por sua vez, deve ser compatível com o Plano Estadual de Gerenciamento Costeiro presente em cada unidade da federação brasileira.

As diretrizes e orientações para implantação do ZEEC leva em conta a importância de qualificar as diversas demandas sociais envolvidas nas diferentes porções dos territórios costeiros.

A qualificação das demandas sociais deve auxiliar uma concepção das tendências de estruturação ou desestruturação da base econômica instalada na área costeira. Ao qualificar as potencialidades existentes do ponto de vista dos recursos naturais disponíveis, da infraestrutura logística instalada, da inserção regional, das características demográficas e socioculturais, o estabelecimento do ZEEC passa a ser instrumento mútuo de ordenamento do território e política inclusiva de governança para as regiões envolvidas.

Conforme previsão no material administrativo publicado no Projeto Orla ${ }^{19}$, o ZEEC é uma modalidade mais restrita do Zoneamento Ecológico-Econômico (ZEE).

O primeiro se limita à Zona Costeira do Brasil, sendo mais estrito e específico, enquanto o segundo pode abranger os territórios de todos os Estados do país, Estado que não possui litoral, e podem delimitar zonas especificas interioranas.

19 BRASIL. Ministério do Meio Ambiente. Secretaria de Qualidade Ambiental; Ministério do Planejamento, Orçamento e Gestão. Secretaria do Patrimônio da União. Projeto Orla: implementação em territórios com urbanização consolidado. Brasília, 2006, p.65-66. 
GÓIS, Rômulo Lima Silva de; VERGES, João Vitor Gobis e LUNA, Braúlio José Carvalhal. Ordenamento do território face às dinâmicas climáticas: comparações entre o projeto orla brasileiro, o zoneamento ecológico-econômico costeiro e o programa buyout estadunidense. Revista Eletrônica Direito e Política, Programa de Pós-Graduação Stricto Sensu em Ciência Jurídica da UNIVALI, Itajaí, v.10, n.4, 30 quadrimestre de 2015. Disponível em: www.univali.br/direitoepolitica - ISSN 1980-7791.

A Lei federal brasileira no $6983 / 1998^{20}$ instituiu a Política Nacional do Meio Ambiente, que prevê entres outros instrumentos o zoneamento ambiental (Inciso II do Artigo 90).

O Decreto Federal brasileiro no 4.297/2002 ${ }^{21}$ que regulamenta o zoneamento ambiental estabelece critérios para a elaboração do Zoneamento EcológicoEconômico (ZEE).

O ZEEC surge com a função de traçar diretrizes quanto aos usos permitidos ou estimulados, considerando as interações entre as faixas terrestres e marítimas da Zona Costeira.

Como instrumento de ordenamento do território que visa regulamentar o uso e ocupação da faixa costeira nos munícipios onde são desenvolvidos o plano de gestão de orla, o ZEEC geralmente é elaborado a partir da articulação entre órgãos públicos federais, estaduais e municipais, dentro do próprio procedimento de implementação do Projeto Orla, possuindo a vantagem de não necessitar de processo legiferante rígido, edição de lei, para passar a ter vigência, sendo instituído por ato administrativo local.

Conforme o Projeto Orla ${ }^{22}$, a elaboração do ZEEC deve basear-se em análises e mapas sínteses das formas de uso e ocupação do espaço, características físicas, socioeconômicas e socioambientais do território costeiro. Tais análises e mapas sínteses devem subsidiar a formulação de propostas para a destinação social, econômica e ambiental de cada área da Zona Costeira.

20 BRASIL. Lei Federal brasileira no $\mathbf{6 . 9 3 8}$, de 31 de agosto de 1981. Dispõe sobre a Política Nacional do Meio Ambiente, seus fins e mecanismos de formulação e aplicação, e dá outras providências". Diário Oficial [da] República Federativa do Brasil, Poder Executivo, Brasília, DF, 02 set 1981. Disponível em < http://www.planalto.gov.br/ccivil_03/leis/l6938.htm>. Acesso em: 04 jun. 2014.

${ }^{21}$ BRASIL. Decreto Federal brasileiro no 4.297, de 10 de julho de 2002. Regulamenta o art. 9o, inciso II, da Lei no 6.938, de 31 de agosto de 1981, estabelecendo critérios para o Zoneamento Ecológico-Econômico do Brasil - ZEE, e dá outras providências. Diário Oficial [da] República Federativa do Brasil, Poder Executivo, Brasília, DF, 11 jul 2002". Disponível em < http://www.planalto.gov.br/ccivil_03/decreto/2002/D4297.htm>. Acesso em: 04 jun. 2014.

22 BRASIL. Projeto Orla: implementação em territórios com urbanização consolidado. p.65-66. 
GÓIS, Rômulo Lima Silva de; VERGES, João Vitor Gobis e LUNA, Braúlio José Carvalhal. Ordenamento do território face às dinâmicas climáticas: comparações entre o projeto orla brasileiro, o zoneamento ecológico-econômico costeiro e o programa buyout estadunidense. Revista Eletrônica Direito e Política, Programa de Pós-Graduação Stricto Sensu em Ciência Jurídica da UNIVALI, Itajaí, v.10, n.4, 30 quadrimestre de 2015 . Disponível em: www.univali.br/direitoepolitica - ISSN 1980-7791.

A articulação de elaboração do ZEEC deve atentar para todo processo, estudos e discussões das oficinas municipais do Projeto Orla, pois o zoneamento, conforme decreto federal brasileiro 5300/2004 ${ }^{23}$, deve levar em conta na sua elaboração, a participação direta da população envolvida, estabelecendo diretrizes quanto aos usos permitidos, proibidos e estimulados, abrangendo sempre a relação entre as faixas terrestres e marítimas da Zona Costeira.

É a partir dessa articulação, que o Plano de Gestão Integrada do Projeto Orla surge como ótimo instrumento que possibilita o detalhamento minucioso das categorias de zoneamento do ZEEC em âmbito local.

Sob uma perspectiva de implantação do Projeto Orla, da construção do Plano de Gestão Integrado e da utilização do ZEEC nas orlas de médias e grandes cidades, o detalhamento se torna inevitável, em razão da multiplicidade de situações urbanas, rurais, ecológicas e econômicas que devem ser consideradas, situações que por ocorrerem em escalas micro-locais passam a ser invisíveis do ponto de vista do ZEEC, mas que com a integração entre esses três mecanismos podem ser consolidados.

Daí a importância desse detalhamento: dar a ver os pequenos territórios das orlas com urbanização consolidada, especialmente as diferentes Unidades de Conservação instituídas por lei, seja de Proteção Integral, seja de Uso Sustentável.

As variáveis que o ZEEC deve analisar e mapear ajudam na compreensão e definição da faixa da orla costeira. Caso o Estado ou a região conte com esse instrumento, vale a pena utilizá-lo no processo de elaboração do Plano de Gestão Integrada do Projeto Orla.

\footnotetext{
${ }^{23}$ BRASIL. Decreto Federal brasileiro no 5.300, de 7 de dezembro de 2004. Regulamenta a Lei no 7.661, de 16 de maio de 1988, que institui o Plano Nacional de Gerenciamento Costeiro PNGC, dispõe sobre regras de uso e ocupação da zona costeira e estabelece critérios de gestão da orla marítima, e dá outras providências. Diário Oficial [da] República Federativa do Brasil, Poder Executivo, Brasília, DF, 8 dez 2004". Disponível em < http://www.planalto.gov.br/ccivil 03/ ato2004-2006/2004/decreto/D5300.htm>. Acesso em: 04 jun. 2014.
} 
GÓIS, Rômulo Lima Silva de; VERGES, João Vitor Gobis e LUNA, Braúlio José Carvalhal. Ordenamento do território face às dinâmicas climáticas: comparações entre o projeto orla brasileiro, o zoneamento ecológico-econômico costeiro e o programa buyout estadunidense. Revista Eletrônica Direito e Política, Programa de Pós-Graduação Stricto Sensu em Ciência Jurídica da UNIVALI, Itajaí, v.10, n.4, 30 quadrimestre de 2015. Disponível em: www.univali.br/direitoepolitica - ISSN 1980-7791.

A utilização das variáveis presentes no ZEEC na elaboração do Plano de Gestão Integrada da orla permitiria a demarcação e classificação de unidades e trechos territoriais para definição de critérios de delimitação da faixa de orla, onde em urbanizações consolidadas, essa demarcação e classificação levariam em conta padrões construtivos de usos e ocupações do solo.

Como paradigma da junção e utilização dos dois instrumentos citados, e como resultado de tal trabalho cooperativo, pode-se analisar as imagens abaixo de classificação e mapeamento de uma parte da faixa litorânea da cidade de Fortaleza, capital do Estado do Ceará no nordeste brasileiro.

A demarcação e classificação de unidades e trechos territoriais, após todas as oficinas municipais e instrumentos de governança propostos no Projeto Orla regionalizado ${ }^{24}$, ajudaria na tomada de decisões políticas mais diretas e coercitivas, ou não coercitivas, a serem adotadas em momento mais à frente, em caso de exigência de medidas públicas com mais urgência a serem adotadas.

Salienta-se, conforme Projeto Orla Fortaleza, que a cartografia encontra-se em meio digital, favorecendo a elaboração de mapas temáticos, zoneamento ambiental e caracterização das áreas prioritárias para o desenvolvimento das ações previstas. Este será de fundamental importância para a composição de projetos paisagísticos, remoção de comunidades em áreas de risco e de preservação permanente, planos de manejo das Unidades de Conservação (UC's) e no ordenamento territorial da orla.

Conforme analisado, a implantação do Projeto Orla no Brasil com a previsibilidade de criação de Planos de Gestão Integrada dos territórios litorâneos e dos Zoneamentos Econômicos-Ecológicos Costeiros, surge como medida de Ordenamento do Território que se apresenta como meio de articulação e coordenação da tomada de decisões políticas, no qual a previsibilidade do

\footnotetext{
24 PREFEITURA MUNICIPAL DE FORTALEZA. Plano de Gestão Integrado da Orla Marítima: Projeto $\quad$ Orla. $\quad$ Fortaleza. $2006 . \quad$ Disponível $\quad$ em: $<$ http://www.fortaleza.ce.gov.br/sites/default/files/semam/arquivos conteudos/p orla.pdf $>$. Acesso em: 04 jun. 2014.
} 
GÓIS, Rômulo Lima Silva de; VERGES, João Vitor Gobis e LUNA, Braúlio José Carvalhal. Ordenamento do território face às dinâmicas climáticas: comparações entre o projeto orla brasileiro, o zoneamento ecológico-econômico costeiro e o programa buyout estadunidense. Revista Eletrônica Direito e Política, Programa de Pós-Graduação Stricto Sensu em Ciência Jurídica da UNIVALI, Itajaí, v.10, n.4, 30 quadrimestre de 2015 . Disponível em: www.univali.br/direitoepolitica - ISSN 1980-7791.

processo de planejamento participativo e colaborativo do território passa a ajudar na criação de visões partilhadas com minimização de conflitos de interesses na construção de um futuro comum, possibilitando convergências, novas coligações de interesses, sendo ainda, meio e solução para ajuda na tomada de decisões políticas, para implementação dessas decisões e para o acompanhamento posterior das mesmas.

\section{O PROgRAMA BUYOUT ESTADUNIDENSE COMO POLÍtICA PÚblicA TERRITORIAL DE ADAPTAÇÃO TRANSFORMACIONAL}

Se por um lado o Projeto Orla brasileiro surge como instrumento de Ordenamento do Território que considera a complexidade social e a importância de uma visão integrada entre Planos de Gestão da Orla marítima e a delimitação de Zoneamentos Especiais de uso e ocupação do território, sob outro prisma existem situações emergenciais e limítrofes onde políticas públicas passam a agir de modo mais coercitivo para possibilitar uma adaptação transformacional da sociedade evitando os impactos crescentes das dinâmicas climáticss e dos eventos climáticos extremos associados, como o Programa Buyout estadunidense.

O Programa Buyout ${ }^{25}$ consiste na aquisição de propriedades imobiliárias e ocorre quando um Órgão Público negocia diretamente a compra dessas propriedades com seus proprietários privados.

Entre as várias razões diferentes para aquisições das propriedades privadas podem ser listadas: o impedimento de construção de obra pública devido a localização do imóvel, ou quando as propriedades encontram-se numa área de

25 Federal emergenCy MANAgement agenCy - FeMA. Hazard Mitigation Assistance Property Acquisition (Buyouts). Disponível em: <http://www.fema.gov/applicationdevelopment-process/hazard-mitigation-assistance-property-acquisition-buyouts $>$. Acesso em: 04 jun. 2014. 
GÓIS, Rômulo Lima Silva de; VERGES, João Vitor Gobis e LUNA, Braúlio José Carvalhal. Ordenamento do território face às dinâmicas climáticas: comparações entre o projeto orla brasileiro, o zoneamento ecológico-econômico costeiro e o programa buyout estadunidense. Revista Eletrônica Direito e Política, Programa de Pós-Graduação Stricto Sensu em Ciência Jurídica da UNIVALI, Itajaí, v.10, n.4, 30 quadrimestre de 2015 . Disponível em: www.univali.br/direitoepolitica - ISSN 1980-7791.

risco, como uma planície de inundação, faixas litorâneas sujeitas a erosão marítima, onde há um forte risco de danos dispendiosos.

A aquisição da propriedade compensa o proprietário com uma porcentagem muito próxima ao valor de mercado do imóvel e também pode cobrir os custos de realocação, podendo ser realizado de forma voluntária ou coercitiva com desapropriação direta da propriedade delimitada.

Conrad et $\mathrm{al}^{26}$ informa que mais de 20 mil voluntários se submeteram ao programa deixando suas propriedades e passaram a aderi-lo por três princípios básicos: recebem assistência significativa e valor de compra justo; enxergam a política pública como utilização eficaz dos fundos públicos pois alivia os gastos na reparação dos danos e impactos provocados pelos eventos extremos; sentem-se agentes preservadores do ambiente, pois veem suas propriedades serem revertidas permanentemente em espaços de lazer e em zonas de proteção ambiental.

O Code Of Federal Regulations ${ }^{27}$ nos seus Títulos 44, 206, 224 e 225, se apresenta como um dos diplomas legais estadunidenses que embasam o programa, já que estabelece que uma política pública deva ser elegível quando visar eliminar ou diminuir ameaças imediatas à vida, à saúde pública e à segurança, sendo autorizada a implantação de programa que diminui os danos significativos à população objetivando a melhoria da propriedade privada ou pública.

${ }^{26}$ CONRAD, D.R.; MCNITT, B.; STOUT, M. Higher Ground: a report on voluntary property buyouts in the nation's floodplains, a common ground solution serving people at risk, taxpayers and the environment. Second Print. Washigton D.C: National Wildlife Federation, 2000, p. 44.4 Disponível em: $<$ http://www.nwf.org/pdf/Water/199807_HigherGround_Report.pdf>.Acesso em: 04 jun. 2014.

27 U.S. GOVERNMENT PRINTING OFFICE - GPO. Code of Federal Regulations. Disponível em: <http://www.gpo.gov/fdsys/pkg/CFR-2002-title44-vol1/content-detail.html>. Acesso em: 04 jun. 2014. 
GÓIS, Rômulo Lima Silva de; VERGES, João Vitor Gobis e LUNA, Braúlio José Carvalhal. Ordenamento do território face às dinâmicas climáticas: comparações entre o projeto orla brasileiro, o zoneamento ecológico-econômico costeiro e o programa buyout estadunidense. Revista Eletrônica Direito e Política, Programa de Pós-Graduação Stricto Sensu em Ciência Jurídica da UNIVALI, Itajaí, v.10, n.4, 30 quadrimestre de 2015. Disponível em: www.univali.br/direitoepolitica - ISSN 1980-7791.

Tendo por parâmetro legal tal legislação especificada, a Federal Emergency Management Agency (FEMA) ${ }^{28}$, além de utilizar o programa para mitigar os riscos provenientes de eventos extremos, passou, em trabalho conjunto com Estados envolvidos e comunidades que aderem ao programa, a utilizá-lo como política pública territorial de adaptação transformacional, uma vez que por lei, a propriedade comprada pela administração pública através do programa deve permanecer um espaço aberto onde são criados parques públicos adaptados, refúgios da vida silvestre e estão a ser transformadas por exemplo em zonas úmidas, dunas, ou outros espaços abertos que atuam como buffers costeiros, absorvendo enchentes em épocas de clima extremo.

O Ordenamento do Território pensado sistematicamente com o programa de compras de imóveis em situações de riscos pela administração pública demonstra caracterizar forte política pública de adaptação às dinâmicas climáticas e eventos climáticos extremos, sendo adotado em espectro e alcance consideráveis em alguns Estados norte-americanos.

Para exemplificar a utilização do programa com o planejamento sistemático do uso e ocupação do território posterior à compra dos imóveis, o programa foi implatado no Mississipi após os eventos climáticos extremos ocasionados pelo furacação Katrina no ano de 2010.

A adaptação transformacional, além das obrigações legais supra-citadas, também parte de um desígnio social do programa em que a população atingida pelo evento extremo passa a receber assitência significativa para compra voluntária de uma nova propriedade com idenização de valor justo baseado em análise de mercado para sua antiga propriedade, possibilitando uma reforma fundiária indireta e conciliatória.

28 FEDERAL EMERGENCY MANAGEMENT AGENCY - FEMA. Hazard Mitigation Assistance Property Acquisition (Buyouts). Disponível em: <http://www.fema.gov/applicationdevelopment-process/hazard-mitigation-assistance-property-acquisition-buyouts $>$. Acesso em: 04 jun. 2014. 
GÓIS, Rômulo Lima Silva de; VERGES, João Vitor Gobis e LUNA, Braúlio José Carvalhal. Ordenamento do território face às dinâmicas climáticas: comparações entre o projeto orla brasileiro, o zoneamento ecológico-econômico costeiro e o programa buyout estadunidense. Revista Eletrônica Direito e Política, Programa de Pós-Graduação Stricto Sensu em Ciência Jurídica da UNIVALI, Itajaí, v.10, n.4, 30 quadrimestre de 2015. Disponível em: www.univali.br/direitoepolitica - ISSN 1980-7791.

O programa, ainda, apresenta-se baseado na observância do princiípio da eficácia dos recursos públicos, já que há um alívio de dispêndio com a recuperação e provimento de ajuda para areas que no futuro poderiam ser atingidas atingidas.

\section{CONSIDERAÇÕES FINAIS}

A análise das dinâmicas climáticas nas cidades litorâneas demonstra como os cidadãos, empresas e agentes políticos das cidades possuem uma clara opção de desenvolvimento que poderá agravar, ou de maneira distinta, limitar os danos que as dinâmicas climáticas poderão produzir no futuro.

Mais importante que isso, para um contexto de corresponsabilidade e governança em vários níveis de atuação, demonstra que através do planejamento urbano proativo e gestão das propriedades terrestres de modo mais eficaz, pode-se reduzir a exposição da população urbana e das infraestruturas a potenciais inundações costeiras.

Caso tal problemática seja pensada em conjunto com a problemática da mudança no ciclo e intensidade das precipitações, as mesmas poderão ser adjetivadas como um dos mais fortes "Calcanhares de Aquiles" a serem contornados pelas decisões políticas e gargalos nas várias áreas do conhecimento enfrentado pela comunidade científica.

Um olhar integrado, mais amplo e estratégico, como no Projeto Orla brasileiro, não deverá ser centrado apenas no vetor de ação sob a perspectiva humana de utilização do território costeiro, mas sim deverá partir do reconhecimento de aspectos como os impactos das dinâmicas climáticas, dinâmicas do litoral, riscos naturais, não só compreendendo as interações terra-mar, mas sim necessitando de intervenções coordenadas ou mesmo integradas a serem desenvolvidas para espaços adequados que não se limitem apenas às características morfológicas 
GÓIS, Rômulo Lima Silva de; VERGES, João Vitor Gobis e LUNA, Braúlio José Carvalhal. Ordenamento do território face às dinâmicas climáticas: comparações entre o projeto orla brasileiro, o zoneamento ecológico-econômico costeiro e o programa buyout estadunidense. Revista Eletrônica Direito e Política, Programa de Pós-Graduação Stricto Sensu em Ciência Jurídica da UNIVALI, Itajaí, v.10, n.4, 30 quadrimestre de 2015. Disponível em: www.univali.br/direitoepolitica - ISSN 1980-7791.

dos centros urbanos litorâneos, mas em estratégias de intervenção para um salto que pense as cidades litorâneas como cidades que cooperam com o mar e com os recursos marinhos.

A estratégia de Ordenamento do Território no litoral adotada pelo Projeto Orla e as delimitações das ZEEC apresentam caráter preventivo e podem ser desenvolvidas instrumentalmente, caso necessário, através de medidas que vão desde a implantação de infraestruturas leves que visam à proteção costeira de inundações provocadas pela subida do nível do mar, tempestades associadas a tufões, até medidas que pensem uma nova relação entre essas infraestruturas, a sociedade no meio urbano litorâneo e os ecossistemas correlacionados, mas que deve ser repensada para agregar intervenções mais rígidas como a desapropriação direta ou indireta por meio de instrumentos legais, como no programa estadunidense Buyout.

Se por um lado o Projeto Orla brasileiro leva em conta a análise das formas de uso e ocupação do território, características físicas, socioeconômicas e socioambientais do território costeiro e passa a ser instrumento de subsídio da formulação de propostas para a destinação social, econômica e ambiental de cada área da Zona Costeira, por outro lado, o Programa Buyout estadunidense apresenta-se como instrumento que deve ser utilizado em momento mais emergencial onde situações limítrofes passam a exigir políticas públicas mais coercitivas que possibilitem uma adaptação transformacional da sociedade, evitando os impactos crescentes dos eventos climáticos associados.

Numa perspectiva comparada, o presente artigo contribui no sentido de revelar que a combinação do Projeto Orla brasileiro para delimitação e análise territorial com a implantação dos ZEEC e Plano de Gestão Costeira combinados com a utilização do programa Buyout estadunidense, onde a instrumentalização de políticas públicas preventivas não se apresentam como promotoras de adaptação possível à sociedade vulnerável, pode constituir solução a ser considerada para enfrentar as problemáticas que envolvem o aumento do nível do mar e da erosão 
GÓIS, Rômulo Lima Silva de; VERGES, João Vitor Gobis e LUNA, Braúlio José Carvalhal. Ordenamento do território face às dinâmicas climáticas: comparações entre o projeto orla brasileiro, o zoneamento ecológico-econômico costeiro e o programa buyout estadunidense. Revista Eletrônica Direito e Política, Programa de Pós-Graduação Stricto Sensu em Ciência Jurídica da UNIVALI, Itajaí, v.10, n.4, 30 quadrimestre de 2015. Disponível em: www.univali.br/direitoepolitica - ISSN 1980-7791.

marítima, num contexto que é preciso pensar e projetar cidades urbanas que cooperem com o mar e com o ambiente.

Desta feita, recomendam-se no âmbito científico abordado pesquisas futuras direcionadas à escolha de alternativas para integrar um projeto ao outro e fazer análises econômicas, principalmente referentes a custo/benefício do Programa Buyout, levantando dados relevantes sobre o andamento das desapropriações já realizadas.

\section{REFERÊNCIAS DAS FONTES CITADAS}

AMBRIZZI, T.; ROCHA, R.; MARENGO, J.; PISNITCHENKO, L.; ALVES, Fernandez. Cenários regionalizados de clima no Brasil para o Século XXI: projeções de clima usando três modelos regionais. Relatório 3. Brasília, 2007.

ARZABE, Jorge. Gestão da Zona Costeira e os Terrenos da Marinha. 60fl. Trabalho de Conclusão de Curso (Curso Intensivo de Pós Graduação em Administração Pública). Fundação Getúlio Vargas. Brasília, 2011, p.23-31 e p.50. Disponível em: http://patrimoniodetodos.gov.br/pasta-dearquivos/GESTaO\%20DA\%20ZONA\%20COSTEIRA\%20E\%200S\%20TERRENOS\% 20DE\%20MARINHA.doc>. Acesso em: 04 de junho de 2014.

BRASIL. Decreto Federal brasileiro no 5.300, de 7 de dezembro de 2004. Regulamenta a Lei no 7.661, de 16 de maio de 1988, que institui o Plano Nacional de Gerenciamento Costeiro - PNGC, dispõe sobre regras de uso e ocupação da zona costeira e estabelece critérios de gestão da orla marítima, e dá outras providências. Diário Oficial [da] República Federativa do Brasil, Poder Executivo, Brasília, DF, 8 dez 2004". Disponível em < http://www.planalto.gov.br/ccivil_03/_ato2004-

2006/2004/decreto/D5300.htm>. Acesso em: 04 jun. 2014.

BRASIL. Decreto Federal brasileiro no 4.297, de 10 de julho de 2002. Regulamenta o art. 9o, inciso II, da Lei no 6.938, de 31 de agosto de 1981, estabelecendo critérios para o Zoneamento Ecológico-Econômico do Brasil - ZEE, e dá outras providências. Diário Oficial [da] República Federativa do Brasil, Poder Executivo, Brasília, DF, 11 jul 2002". Disponível em < http://www.planalto.gov.br/ccivil_03/decreto/2002/D4297.htm>. Acesso em: 04 jun. 2014.

BRASIL. Lei Federal brasileira no 6.938, de 31 de agosto de 1981. Dispõe sobre a Política Nacional do Meio Ambiente, seus fins e mecanismos de 
GÓIS, Rômulo Lima Silva de; VERGES, João Vitor Gobis e LUNA, Braúlio José Carvalhal. Ordenamento do território face às dinâmicas climáticas: comparações entre o projeto orla brasileiro, o zoneamento ecológico-econômico costeiro e o programa buyout estadunidense. Revista Eletrônica Direito e Política, Programa de Pós-Graduação Stricto Sensu em Ciência Jurídica da UNIVALI, Itajaí, v.10, n.4, 30 quadrimestre de 2015. Disponível em: www.univali.br/direitoepolitica - ISSN 1980-7791.

formulação e aplicação, e dá outras providências". Diário Oficial [da] República Federativa do Brasil, Poder Executivo, Brasília, DF, 02 set 1981. Disponível em < http://www.planalto.gov.br/ccivil_03/leis/l6938.htm>. Acesso em: 04 jun. 2014.

BRASIL. Ministério do Meio Ambiente. Secretaria de Qualidade Ambiental; Ministério do Planejamento, Orçamento e Gestão. Secretaria do Patrimônio da União. Projeto Orla: implementação em territórios com urbanização consolidado. Brasília, 2006, p.65-66.

BURNIAX, J.; CHATEAU, J.; DELLINK, R.; DUVAL, R.; JAMET. S. The economics of climate change mitigation: how to build the necessary global action in a cost-effective manner?. Paris: OECD Economics Departament Working Papers, 2008, p.109-110.

CONRAD, D.R.; MCNITT, B.; STOUT, M. Higher Ground: a report on voluntary property buyouts in the nation's floodplains, a common ground solution serving people at risk, taxpayers and the environment. Second Print. Washigton D.C: National Wildlife Federation, 2000, p. 44. Disponível em: <http://www.nwf.org/pdf/Water/199807_HigherGround_Report.pdf $>$. Acesso em: 04 jun. 2014.

DUVAL, R.; MAISONNEUVE, C. Long-run GDP Growth Scenarios for the World Economy. Paris: OECD Economics Departament Working Papers, 2009, p. 16-17.

FEDERAL EMERGENCY MANAGEMENT AGENCY - FEMA. Hazard Mitigation Assistance - Property Acquisition (Buyouts). Disponível em: <http://www.fema.gov/application-development-process/hazard-mitigationassistance-property-acquisition-buyouts>. Acesso em: 04 jun. 2014.

FERRÃO, João. Ordenamento do Território como Política Pública. 2 ed. Lisboa: Fundação Calouste Gulbenkian, 2015, p. 46-89 e p. 25-41.

HAJER, M.; GRIJZEN, J.; VANT'T. S. Strong Stories. How Dutch are Reiventing Spatial Planning. Rotterdam: 010 Publishers, 2010.

\footnotetext{
INTERGOVERNAMENTAL PANEL ON CLIMATE CHANGE - IPCC. Climate Change 2013: the physical science basis. Disponível em: <http://www.climatechange2013.org/images/report/WG1AR5_ALL_FINAL.pdf>. Acesso em: 04 jun. 2014.
}

JAMET, S.; MORLOT-CORFEE, J. Assessing the Impacts of Climate Change: a literature review, Paris: OECD Economics Departament Working Papers, no 693, 2009, p. 20-21.

LOMBARDO, Magda Adelaide. Análise das Mudanças Climáticas nas Metrópoles: 0 exemplo de São Paulo e Lisboa. In: SILVA, Aparecida Guarniere Ortigoza; 
GÓIS, Rômulo Lima Silva de; VERGES, João Vitor Gobis e LUNA, Braúlio José Carvalhal. Ordenamento do território face às dinâmicas climáticas: comparações entre o projeto orla brasileiro, o zoneamento ecológico-econômico costeiro e o programa buyout estadunidense. Revista Eletrônica Direito e Política, Programa de Pós-Graduação Stricto Sensu em Ciência Jurídica da UNIVALI, Itajaí, v.10, n.4, 30 quadrimestre de 2015 . Disponível em: www.univali.br/direitoepolitica - ISSN 1980-7791.

CORTEZ, Ana Tereza. Da produção ao consumo: impactos socioambientais no espaço urbano. Rio Claro: Ed. Cultura Acadêmica, 2009.

MUEHE, Dieter. Definição de limites e tipologias da orla sob os aspectos morfodinâmico e evolutivo. In: BRASIL. Ministério do Meio Ambiente. Secretaria de Qualidade Ambiental; Ministério do Planejamento, Orçamento e Gestão. Secretaria do Patrimônio da União. Projeto orla - subsídios para um projeto de gestão, Brasília, 2006, p. 11.

PELLING, M.; NAVARRETE, Manuel. From Resilience to Transformation: the adaptive cyrcle in two Mexican urban centers. Ecology and Society, v. 16, n.2, art. 11 2011. Disponível em: <http://www.ecologyandsociety.org/vol16/iss2/art11/ $>$. Acesso em: 04 jun. 2014.

PREFEITURA MUNICIPAL DE FORTALEZA. Plano de Gestão Integrado da Orla Marítima: Projeto Orla. Fortaleza. 2006. Disponível em: <http://www.fortaleza.ce.gov.br/sites/default/files/semam/arquivos_conteudos/ p_orla.pdf $\geq$. Acesso em: 04 jun. 2014.

ORGANIZAÇÃO PARA COOPERAÇÃO E DESENVOLVIMENTO ECONÔMICO - OCDE. Competitive Cities in the Global Economy. Paris: OECD Publications, 2006, p.1.

ORGANIZAÇÃO PARA COOPERAÇÃO E DESENVOLVIMENTO ECONÔMICO - OCDE. Ranking Port Cities with High Exposure and Vulnerability to Climate Extremes: Exposure Estimates. Environmental working papers, Paris, n. 1, 2008, p. 6382.

SANTOS, Filipe Duarte. Alterações Globais. Lisboa: Fundação Francisco Manuel dos Santos, 2012.

U.S ARMY CORP OF ENGINEERS. The Mississippi coastal improvements program: draft supplemental environmental impact statement. Disponível em: <http://www.sam.usace.army.mil/Missions/ProgramandProjectManagement/MsC IPProgram.aspx>. Acesso em: 04 jun. 2014.

U.S. GOVERNMENT PRINTING OFFICE - GPO. Code of Federal Regulations. Disponível em: <http://www.gpo.gov/fdsys/pkg/CFR-2002-title44-vol1/contentdetail.html>. Acesso em: 04 jun. 2014.

Submetido em: Julho/2015

Aprovado em: Outubro/2015 